\title{
Interesting fellow or tough old bird? $3^{\text {rd }}$ person male referents in Ontario
}

\author{
Karlien Franco (KU Leuven, University of Toronto) \& Sali A. Tagliamonte (University of Toronto)
}

\begin{abstract}
English has many words to refer to an adult man, e.g. man, guy, dude, and these are undergoing change in Ontario dialects. This paper analyzes the distribution of these and related forms using data collected in Ontario, Canada. In total, $N=6788$ tokens for 17 communities were extracted and analyzed with a comparative sociolinguistics methodology for social and geographic factors. The results demonstrate a substantive language change in progress with two striking patterns. First, male speakers in Ontario were the leaders of this change in the past. However, as guy gained prominence across the $20^{\text {th }}$ century, women started using it as frequently as men. Second, these developments are complicated by the complexity of the sociolinguistic landscape. There is a clear urban vs. peripheral division across Ontario communities that also involves both population size and distance from the large urban centre, Toronto. Further, social network type and other local influences are also important. In sum, variation in $3^{\text {rd }}$ person singular male referents in Ontario dialects provides new insight into the co-occurrence and evolution of sociolinguistic factors in the process of language change.
\end{abstract}

Key words: Canadian English, language variation, language change, guy, homogenization

\section{Introduction}

The English language has many words to refer to an adult man, such as 'guy', 'man', 'fellow', 'chap' and, surprisingly in specific contexts, 'bird'. These $3^{\text {rd }}$ person singular male nouns are prone to variation and change in Ontario dialects (see Tagliamonte to appear). For example, alternative forms can be found in similar grammatical contexts $(1 \mathrm{a}, \mathrm{b})$, and variation even occurs within single utterances (1c):

(1) a. He's just the guy who's got all the stuff (Hayden Rubanich, M, 18, Kapuskasing)

b. Uh he was a black fellow that was vice-principal at the high-school. (Adam Butenko M, 59, Kapuskasing)

c. I knew the man. A chap I went to school with. (Walt Walters, M, 85, Belleville)

However, little research exists into the distribution of these variants. One exception is Tagliamonte (to appear), in which the pronominal system of reference to $3^{\text {rd }}$ person singular males was shown to be undergoing reorganization in the dialects of Ontario. More specifically, a pattern of increasing use of 'guy' over time, at the expense of other variants, e.g. 'dude', 'lad', 'fellow', 'gentleman' and 'man', was discovered and the pattern was shown to be correlated with the nature of cities and towns across Ontario. Furthermore, in contrast to Principles 3 and 4 (Labov 2001), male speakers - not female speakers - were found to be ahead in the change in that they used the novel variant 'guy' the most.

A few studies have examined the meaning, use and diachronic evolution of one or the other of these variants. Both 'guy' and 'dude' underwent semantic shift at earlier points in time, which was a prerequisite for their present-day use as nouns for an indefinite male individual. 'Dude' was originally used for a specific type of individual, a dandy, i.e. a person who dresses fashionably, but in contemporary North American English 
now the word indexes “cool solidarity” (Kiesling 2004:282). 'Guy' was originally a proper name, and the name of England's arch enemy, Guy Fawkes (Metcalf 2019). Fawkes' failed attempt to blow up the House of Parliament was celebrated every year on November $6^{\text {th }}$ with bonfires, in which an effigy of Guy Fawkes, known as 'the Guy', was burnt. After a while, the word 'guy' underwent semantic bleaching, and became used in other contexts beyond that of the Guy Fawkes effigy, albeit with a negative connotation, according to Metcalf (2019:108), "a male human of the lowest order." Over the following centuries, more semantic bleaching occurred, which ultimately resulted in its present-day use: for reference to second person plurals of any gender (e.g. 'you guys'), and for generic reference to males (e.g. 'this guy'). The fact that referents for $3^{\text {rd }}$ person singular males have this rich history of variation and change leads us to pursue further investigation into the state of this variable use of words in Ontario.

In this paper, we conduct a comparative sociolinguistic analysis (see Tagliamonte 2013) of the $3^{\text {rd }}$ person singular male nouns. We build on Tagliamonte (to appear) but go beyond that study in two ways. First, we expand the envelope of variation and examine a larger number of possible variants. Second, we broaden the geographical scope by including a larger number of Ontario communities in the analysis. The communities that we examine differ on various socio-demographic levels, not only their population size but also degree of urbanization, geographic distance to the urban centre of Toronto, the ethnic composition of their founding populations and the current proportion of Anglophones and Francophones. Consequently, by investigating this complex sociolinguistic landscape, we provide insight into the effect of the interaction between sociolinguistic and geographic features on a language change in progress.

\section{The Ontario Dialects Project}

The data come from the Ontario Dialects Project at the time of writing (most recently Tagliamonte 20132018). This archive contains materials collected from diverse locations in Ontario (Figure 1). It comprises data collected in the urban centre of Ontario, and the largest city in Canada, Toronto (The Toronto English Archive, Tagliamonte 2003-2006) as well as in many smaller communities across Ontario. The data is primarily sociolinguistic interviews (oral histories) with locals, conducted between 2003 and 2018. For some of the communities, diachronic materials are also available. Only individuals who were born and/or raised in their community from a young age are included in the database. The combination of synchronic and diachronic data offers an apparent time perspective of over 100 years and in some cases real time comparisons (e.g. Ottawa Valley, see Jankowski and Tagliamonte 2017). In total, the Ontario Dialect Archive contains 11,034,676 words (May 20, 2019). 


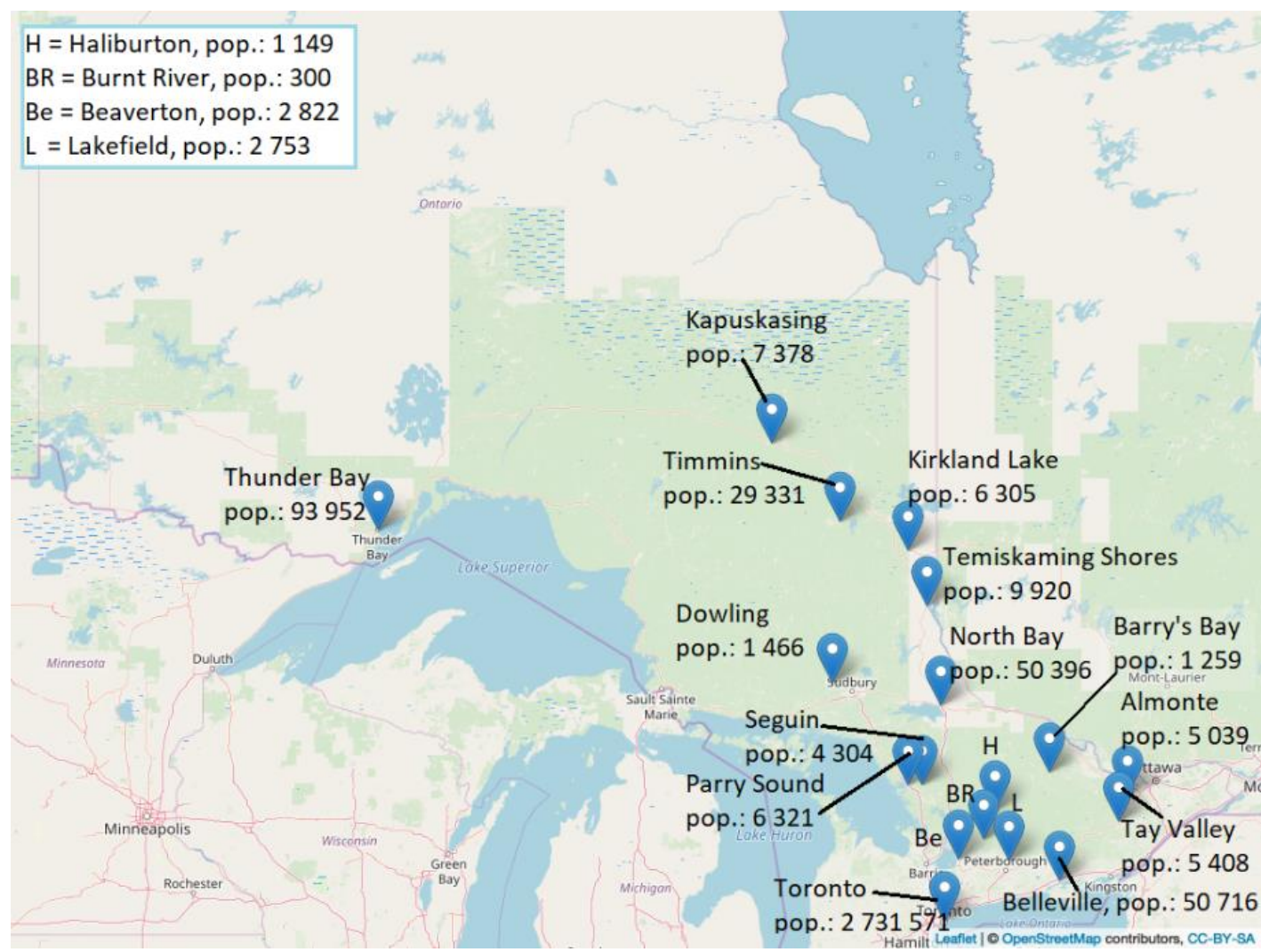

Figure 1: Map of the communities included in the Ontario Dialects Project

Figure 1 shows the communities included in the sample, which are geographically spread out across Ontario. Toronto, located in the far south of the province, on the shore of Lake Ontario, is a very diverse city, with over 2.5 million inhabitants (Statistics Canada 2017). To examine how language change evolves in Ontario, it is crucial to consider that the other communities are characterized by geographic and socio-demographic features that may affect this process.

First, it is well-known from dialectological and dialectometric research that geographical distance can influence the diffusion of linguistic variants (e.g. Goebl 2006, Labov 2007, Séguy 1971). The distance between Toronto and the communities in the sample ranges between $110 \mathrm{~km}$ (Beaverton) and 1,380 km (Thunder Bay) by road. However, the communities differ with regard to other correlates of linguistic variation and change as well, such as their population size and their settlement history. Table 1 provides figures for population size and British Isles ethnicity for the smaller communities in Ontario. Because some of the hamlets where data were collected are part of a larger municipality, viz. Burnt River (Kawartha Lakes), Christie and Swords (which both belong to the Seguin Township) and Wilno (Barry's Bay), we only have access to information at the level of the municipality. 


\begin{tabular}{|c|c|c|c|c|c|c|}
\hline Community & $\begin{array}{l}\text { Population size } \\
\text { (2016) }\end{array}$ & $\begin{array}{l}\text { Total Brit- } \\
\text { ish Isles } \\
\text { ethnicity }\end{array}$ & $\begin{array}{l}\text { English } \\
\text { ethnicity }\end{array}$ & $\begin{array}{l}\text { Irish } \\
\text { ethnicity }\end{array}$ & $\begin{array}{l}\text { Scottish } \\
\text { ethnicity }\end{array}$ & $\begin{array}{l}\text { Year of } \\
\text { recording }\end{array}$ \\
\hline Toronto & $2,731,571$ & $22 \%$ & $12 \%$ & $10 \%$ & $9 \%$ & $2003-2004^{1}$ \\
\hline Almonte & 5,039 & $66 \%$ & $30 \%$ & $38 \%$ & $36 \%$ & $\begin{array}{l}\text { 1975-1980, } \\
2012-2014\end{array}$ \\
\hline Tay Valley & 5,665 & $66 \%$ & $31 \%$ & $37 \%$ & $36 \%$ & 2013-2014 \\
\hline Lakefield $^{2}$ & 2,753 & $65 \%$ & $42 \%$ & $28 \%$ & $29 \%$ & 2007,2012 \\
\hline Beaverton & 2,822 & $64 \%$ & $40 \%$ & $23 \%$ & $30 \%$ & 2013 \\
\hline $\begin{array}{l}\text { Kawartha Lakes } \\
\text { (Burnt River) }^{3}\end{array}$ & 75,423 & $63 \%$ & $41 \%$ & $26 \%$ & $26 \%$ & $2007-2008$ \\
\hline Haliburton & 1,149 & $60 \%$ & $41 \%$ & $28 \%$ & $29 \%$ & 2012 \\
\hline Belleville & 50,716 & $58 \%$ & $34 \%$ & $27 \%$ & $23 \%$ & $\begin{array}{l}1974-1975, \\
2007-2008\end{array}$ \\
\hline Parry Sound & 6,321 & $58 \%$ & $38 \%$ & $26 \%$ & $25 \%$ & $\begin{array}{l}\text { 1973-1985, } \\
\text { 1989-1994, } \\
2016,2018\end{array}$ \\
\hline $\begin{array}{l}\text { Seguin Township } \\
\text { (Christie/Swords) }\end{array}$ & 4,304 & $39 \%$ & $41 \%$ & $24 \%$ & $28 \%$ & $\begin{array}{l}1982 \\
2015-2017\end{array}$ \\
\hline $\begin{array}{l}\text { Barry's Bay } \\
\text { (Wilno) }\end{array}$ & 1,259 & $33 \%$ & $16 \%$ & $22 \%$ & $9 \%$ & 2014 \\
\hline
\end{tabular}

Table 1: Population size and ethnicity information (Statistics Canada 2017) and year of recording of sociolinguistic interviews for Toronto and the northern communities

The Table confirms that these communities are generally small towns with populations ranging between 1,149 in Haliburton to around 5,665 in Tay Valley (Statistics Canada 2017). These communities are also characterized by tight social networks (cf. Tagliamonte 2014 and Tagliamonte \& Denis 2014). They were settled by a varying mix of Irish, Scottish or other British immigrants in the first quarter of the $19^{\text {th }}$ century, which is still exemplified by the fact that a relatively high percentage of their inhabitants have the British Isles as their ancestry. Belleville, a city located along Highway 401, about two hours by car from Toronto, is an exception to this pattern. Like Toronto, it is situated on the shores of Lake Ontario and had a large founding population of Loyalists after the American Revolution at the end of the $18^{\text {th }}$ century. It currently has a population size of 50,716 (Statistics Canada 2017).

\footnotetext{
${ }^{1}$ The Toronto corpus also contains a few sociolinguistic interviews from 2002, 2005, 2007, 2008, 2010, 2011 and 2013 but the largest proportion of the data (80\%) comes from interviews in 2003-2004.

${ }^{2}$ The Ontario Dialects Project also contains four sociolinguistic interviews from the city of Peterborough. As not enough data are available from this community to warrant a reliable analysis, we combine them with the Lakefield data, a town very close-by.

${ }^{3}$ Although this table shows the figures for Kawartha Lakes, the sociolinguistic interviews were mostly conducted in Burnt River and other hamlets belonging to Kawartha Lakes. These hamlets have a much smaller population size (e.g. less than 300 in Burnt River, see Tagliamonte 2014:202).
} 


\begin{tabular}{|l|l|l|l|l|l|l|}
\hline Community & $\begin{array}{l}\text { Population } \\
\text { size (2016) }\end{array}$ & $\begin{array}{l}\text { Total Brit- } \\
\text { ish Isles } \\
\text { ethnicity }\end{array}$ & $\begin{array}{l}\text { English } \\
\text { ethnicity }\end{array}$ & $\begin{array}{l}\text { Irish } \\
\text { ethnicity }\end{array}$ & $\begin{array}{l}\text { Scottish } \\
\text { ethnicity }\end{array}$ & $\begin{array}{l}\text { Year of } \\
\text { recording }\end{array}$ \\
\hline Toronto & $2,731,571$ & $22 \%$ & $12 \%$ & $10 \%$ & $9 \%$ & $2003-2004$ \\
\hline North Bay & 50,396 & $51 \%$ & $28 \%$ & $23 \%$ & $21 \%$ & $2009-2010$ \\
\hline $\begin{array}{l}\text { Temiskaming } \\
\text { Shores }\end{array}$ & 9,920 & $46 \%$ & $28 \%$ & $20 \%$ & $20 \%$ & 2011 \\
\hline Kirkland Lake & 6,305 & $45 \%$ & $25 \%$ & $18 \%$ & $16 \%$ & $\begin{array}{l}1983,1990, \\
2011\end{array}$ \\
\hline Thunder Bay & 93,952 & $45 \%$ & $26 \%$ & $18 \%$ & $20 \%$ & $2007-2008$ \\
\hline $\begin{array}{l}\text { Timmins } \\
\text { (South Porcupine) }\end{array}$ & 29,331 & $36 \%$ & $20 \%$ & $15 \%$ & $13 \%$ & $2010-2011$ \\
\hline Dowling & 1,466 & $35 \%$ & $16 \%$ & $17 \%$ & $13 \%$ & 2015 \\
\hline Kapuskasing & 7,378 & $21 \%$ & $14 \%$ & $8 \%$ & $7 \%$ & 2016 \\
\hline
\end{tabular}

Table 2: Population size and ethnicity information (Statistics Canada 2017) and year of recording of sociolinguistic interviews for Toronto and the northern communities

The Northern communities also differ in population size, but they are generally mid-sized cities (Table 2). Crucially, the history of these communities is strikingly different from those further south, which may give rise to distinct language patterns (Tagliamonte 2014). The northern areas of the province developed later with a much more varied mix of migrants. Some English-origin settlers moved north but extensive migrations from both the UK and Europe began at that time as people were recruited to work in the mines or lumber camps. This made northern Ontario multi-ethnic from the beginning. There are minor differences in the distribution of ancestral ethnicities in the north depending on the location. For example, in the 2016 census, Kapuskasing's population is $41 \%$ French origin and $34 \%$ of the population are European (excluding British origin). Although the proportion of people of French descent is lower in Thunder Bay (16\%), 34\% of the inhabitants are European (excluding British) as well. In contrast, Toronto is quite distinct having had many layers of migration over the entire history of the province to the point where now over half of the population was not born in Canada. In sum, in the south, the towns are predominantly made up of British origin people, while in the north the population is more diverse, still predominately white, but not necessarily British.

Due to their different socio-historic background and geographic spread, the Ontario dialects offer an ideal site to examine a linguistic change in progress in Ontario English. More specifically, the city of Toronto is expected to play a large role in the diffusion of the innovative forms and the change may be at a further developed stage there. Additionally, we may find different patterns of linguistic variation in the northern communities than in the small towns further south (cf. Britain 2013:478-483). First, geography may play a role. The wave-model of linguistic diffusion would predict that the communities closer to Toronto would adopt changes starting in Toronto more extensively. Alternatively, population size may have an effect as well. In the gravity model (e.g. Trudgill 1974), the diffusion of a linguistic change is hypothesized to be correlated with population size and inversely correlated with geographical distance. In Ontario, this pattern would be found if the change is more evolved in Belleville (which is close to Toronto and has a large 
population size) and in the larger cities in the north than in the small communities inbetween. ${ }^{4} \mathrm{~A}$ similar pattern would be predicted by the cascade model (e.g. Labov 2003), which puts less emphasis on the importance of distance. Third, the social stratification of the Ontario Dialects Project data allows us to examine the influence of social features on variation and change in the system. Next to social correlates, the diachronic evolution of the change in the $20^{\text {th }}$ century can be examined by adopting an apparent-time perspective. Fourth, due to the historical differences between the northern and more southerly communities, and due to differences in the founding populations, we may find that specific forms are more frequent in certain locations (e.g. Scots and Irish variants in Almonte and Tay Valley, which have the highest proportion of inhabitants of Scottish and Irish descent).

\section{Methods}

\subsection{Dependent variable}

Variation and change in nouns used to refer to $3^{\text {rd }}$ person male individuals has not been researched extensively, particularly not from a quantitative perspective. We first collected a list of words that can refer to a male individual in present-day Canadian English by consulting the Historical Thesaurus of the OED ${ }^{5}$, an online thesaurus of English ${ }^{6}$ and various online dictionaries of varieties in the UK. ${ }^{7}$ After removing obsolete forms and variants that are not used in Ontario dialects, we were left with a set of 12 lexical items: 'guy', 'man', 'fellow' (and spelling variants 'fella' and 'feller'), 'lad', 'gentleman', 'chap', 'buddy'/'bud', 'dude', 'mate', 'buck', 'geezer' and 'bloke'. Many of these variants are generally associated with a particular dialect area or variety of English. According to the $\mathrm{OED}^{8}$, for instance, 'guy' is originally an American English variant (but see Metcalf 2019), and 'bud' and 'buddy' are chiefly used in the US. 'Lad' is common in Scottish English (Jennifer Smith p.c., December 10, 2019), as in (2), but is outdated in American English according to the Cambridge dictionary. The Merriam-Webster and the Cambridge dictionaries record 'chap' as informal British English. In Scots, 'chap' is associated with the "upper class of olden times" but it remains prevalent in rural working-class areas in Scotland (Jennifer Smith p.c., December 10, 2019), as in (3). As the communities in our dataset differ with regard to the ancestry of their population, these varietal differences may explain some of the patterns that we find.

(2) I got to ken Ian McMillan, a nicer lad you could na've got. (BCK) ${ }^{9}$

(3) And there's another chap there and another man with him, an older man. [...] He was a good laugh. Nice bloke. [...] But he's full of energy, you know? The other chap that was with him, he was a bit quieter. $(\mathrm{BCK})^{10}$

\footnotetext{
${ }^{4}$ Testing whether the mathematic predictions of the model are borne out in the data, falls outside the scope of our paper.

${ }^{5}$ http://www.oed.com/thesaurus, Accessed on April 17, 2019.

6 https://www.thesaurus.com, Accessed on April 17, 2019.

${ }^{7}$ https://dsl.ac.uk, Accessed on December 10, 2019; https://dictionary.cambridge.org/, Accessed on May 1, 2019; https://www.merriam-webster.com/dictionary/, Accessed on May 1, 2019.

${ }^{8}$ http://www.oed.com, Accessed on May 1, 2019.

${ }^{9}$ All BCK examples are from Buckie English courtesy of Jennifer Smith (Smith 2013-2016, Smith et al. 2019).

${ }^{10}$ Note the $3^{\text {rd }}$ person singular male nouns in variation in contemporary rural Scots dialects.
} 
We extracted all the tokens for these words from the corpus and analyzed whether their referential meaning is constant, i.e. whether they refer to a single male individual. ${ }^{11}$ Tokens with a different meaning (e.g. 'man' in the sense of 'husband' as in 4), as well as tokens in non-variable contexts were excluded. More specifically, we did not include tokens in which the word type is used adjectivally (5), as a vocative (6) or as a discourse marker (7). Furthermore, as is common in variationist practise, we also excluded fixed expressions (8a,b). In total, this resulted in a dataset containing $\mathrm{N}=6788$ tokens for 19 communities in Ontario.

(4) When we got to Pickerel Station, my- my husband wouldn't wait for the train which went up later. He took me and those two kids and made us walk up that track, for four miles! [...] Oh, that was like a nightmare. (Interviewer: You'd be afraid a train would come.) Oh, terrible. I never was used to railroads. See where we lived up at Dillon, there was no railroads. [...] But they were- those people lived beside the tracks so they were used to it. And my man was a man that, if he said, "Do it," you did it. You see? So there was no arguing. (Maude Schiff, F, 78, Parry Sound)

(5) Some of my guy friends in high school would like do coke at school and like, whatever, and um, (scoffs) I don't really know what they're doing right now. (Hilary MacBain, F, 27, Dowling)

(6) We were walking down the street and we turn the corner and this random guy went like "Yo buddy come here!" and my brother was like "Okay." (Mark Quinton, M, 22, South Porcupine (Timmins))

(7) Like some people I dread seeing them because I'm just like "Oh man she 's gonna get on my nerves" but J. I never dread seeing you-know? (Clara Felipe, F, 19, Toronto)

(8) a. And told them that I had picked him up on a couple occasions and he was- he was a perfect gentleman, he done his job. (Thaddeus Bickley, M, 30, Kirkland Lake)

b. Archie used to go out and milk the cow for Josh's father, you know. But James was a tough old bird. (Sheena Joplin, F, 73, Christie)

\subsection{Independent variables}

In this study, we focus on sociolinguistic factors that may influence variation and change in the identified set of $3^{\text {rd }}$ person singular nouns used for male individuals. As explained above, we expect that the geographical and socio-demographic differences between the small southerly communities and the larger northern ones and Toronto will affect the distribution of the variants for $3^{\text {rd }}$ person singular male referents. Consequently, the first variable that we consider is the community of the speaker. Because in some of the communities that were included in the dataset, the data are too sparse, we grouped them together with other close-by and socio-demographically similar locations in the analysis. The total number of tokens per (grouped) community is presented in Table 3.

\footnotetext{
${ }^{11}$ As two anonymous reviewers point out, collocational patterns may reveal diverging uses of the variants. For this reason, we also verified that the contexts included in the analysis are truly interchangeable by means of a collocation analysis and we found no significant differences in the correlations of any of the variants included in the variable context.
} 


\begin{tabular}{|l|l|}
\hline Community & N \\
\hline Almonte \& Tay Valley & 884 \\
\hline Beaverton & 183 \\
\hline Belleville & 280 \\
\hline Lakefield \& Burnt River (Kawartha Lakes) & 261 \\
\hline Christie/Swords (Seguin Township) & 216 \\
\hline Dowling & 145 \\
\hline Haliburton & 218 \\
\hline Kapuskasing & 562 \\
\hline Kirkland Lake & 691 \\
\hline North Bay & 214 \\
\hline Parry Sound & 537 \\
\hline South Porcupine (Timmins) & 286 \\
\hline Temiskaming Shores & 456 \\
\hline Thunder Bay & 117 \\
\hline Toronto & 1490 \\
\hline Wilno (Barry's Bay) & 248 \\
\hline
\end{tabular}

Table 3: Number of tokens per (grouped) community

Second, we test the diachronic evolution of the use of the $3^{\text {rd }}$ person male nouns by adopting an apparenttime perspective. The data contain sociolinguistic interviews with speakers born between 1879 and 2001, although individuals born before 1920 are fewer in number. We use the year of birth of the speaker in the analysis, rather than their age at the time of the interview, as previous research has shown that relying on speaker age can sometimes hide patterns of age grading (Jankowski \& Tagliamonte 2017).

Third, we analyse the effect of broad social factors that are known to influence language change in progress, viz. (perceived) speaker sex, education level (with or without post-secondary education) and occupation level (blue collar, white collar or student). The nature of the fieldwork and data collection protocols that were used to elicit the data does not enable us to include more detailed information about the individuals, such as their gender identity, or nuances of their education or occupation level. We rely on the existing documentation and content of the interviews.

Principles 3 (change from above, cf. Labov 2001) and 4 (change from below) predict that women are the leaders of linguistic change for diffusing variants. However, recall that Tagliamonte (to appear) found that men were ahead in the use of the $3^{\text {rd }}$ person singular male noun 'guy'. As a result, examining the distribution of the variants according to these sociolinguistic features, together with the apparent-time perspective, will provide insight to how the variants have spread across the Ontario communities. 


\subsection{Methods}

The analysis consists of two parts. First, as is traditional in comparative sociolinguistic practice, we inquire into the general distribution of the variants over the dependent variable and between the independent variables. Below, we show the distribution of all the variants in apparent time, by relying on the decade of birth and on the community of the speakers. We use a conditional inference tree to corroborate that a language change in progress is present in the data.

As the tree confirms that there is indeed a shift towards 'guy', the next step is to zoom in on sociolinguistic and geographic factors that may explain the evolution of this change. Because the dataset is highly complex, we use a mixed-effects logistic regression model to assess the simultaneous effect of all the social factors. As the response variable has multiple variants, we use a binary operationalization of the $3^{\text {rd }}$ person nouns (viz. 'guy' or anything but 'guy'). As predictor variables, we consider all the sociolinguistic factors (year of birth, sex, education level and occupation level) and the interaction between them.

Since both the speakers and the communities in the corpus can be considered random variables due to the fact that they are randomly sampled from a larger population of the speakers' respective communities (e.g. Baayen 2008), the model that we use contains a random intercept for speaker nested in community. ${ }^{12}$ This approach differs from many other analyses in sociolinguistics in the sense that the geographical location of a speaker is generally included in a regression model as a fixed effect, rather than as a random effect. However, this approach has two benefits. On the one hand, it allows us to faithfully represent the structure of the data by explicitly considering the fact that the (randomly sampled) speakers only belong to a single community, and that the communities are a (random) subset of all the communities in Ontario. On the other hand, including community in particular as a random rather than as a fixed effect has the added practical benefit of not having to regroup communities into larger wholes. More specifically, in regression modelling, the number of regressors that can be supported by the data without overfitting depends on the distribution of the response variable (Speelman 2014). Since we have data for 16 (grouped) communities in our dataset, including this variable as a fixed effect would greatly limit the number of additional factors and interaction effects that can be examined in the analysis, especially given the relatively low token counts for some of the communities (see Table 3 above). By using community as a random effect, however, this problem is eliminated. Furthermore, we can inspect the random intercepts per community to examine to which extent they differ with regard to their use of the incoming form, 'guy'.

\section{Results}

\subsection{Distribution of the nouns}

Table 4 provides an overview of the distribution of the $3{ }^{\text {rd }}$ person singular male variants. The Table shows that 'guy' is by far the most frequent variant in the dataset $(57.82 \%)$, with the second most frequent noun 'man' only occurring in $21.88 \%$ of the tokens and the variant in third position, 'fellow'/'fella'/'feller', only occurring in $10.90 \%$ of the observations.

\footnotetext{
${ }^{12}$ We use a nested random-effects structure because the speakers in the dataset are all inhabitants of a single community.
} 


\begin{tabular}{|l|l|l|}
\hline Noun & $\mathrm{N}$ & $\%$ \\
\hline guy & 3925 & $57.82 \%$ \\
\hline man & 1485 & $21.88 \%$ \\
\hline fellow/fella/feller & 740 & $10.90 \%$ \\
\hline lad & 231 & $3.40 \%$ \\
\hline gentleman & 127 & $1.87 \%$ \\
\hline chap & 108 & $1.59 \%$ \\
\hline buddy/bud & 77 & $1.13 \%$ \\
\hline dude & 64 & $0.94 \%$ \\
\hline mate & 26 & $0.38 \%$ \\
\hline buck & 2 & $0.03 \%$ \\
\hline geezer & 2 & $0.03 \%$ \\
\hline bloke & 1 & $0.01 \%$ \\
\hline total & 6788 & $100 \%$ \\
\hline
\end{tabular}

Table 4: Distribution of $3^{\text {rd }}$ person male noun variants in the dataset

Most of the other variants occur very infrequently. 'Bloke' is only used once by a 59-year-old male from Thunder Bay (9). Interestingly, in the following sentence, the speaker uses 'guy'. 'Geezer' occurs twice, in a single utterance by a 47-year-old male from South Porcupine (10). 'Buck' also occurs twice, and in both cases it is used by a speaker telling a story about a younger version of himself (11). Because these latter three variants, 'buck', 'geezer' and 'bloke', are highly infrequent, we do not include them in our further analyses.

(9) And ah he's kind of strange bloke but he's pretty- he pretty nice though. He's a nice guy, you know. (James Walker, M, 59, Thunder Bay)

(10) You're going to think I'm an old geezer here. That old geezer! (Matthew Pupich, M, 47, South Porcupine)

(11) a. I was the young buck around here that had a truck. (Kurt Steiger, M, 59, Christie)

b. When I'd get up in the morning, I'd have breakfast, when I was a young- a young buck. (Richard Masters, M, 58, North Bay)

Figure 2 shows the distribution of the $3^{\text {rd }}$ person male variants per community. The communities on the $x-$ axis are organized by increasing proportion of 'guy'. The x-axis also indicates the total token count per community. The variants that occur less than 100 times are coded as 'other' (see Table 4). 


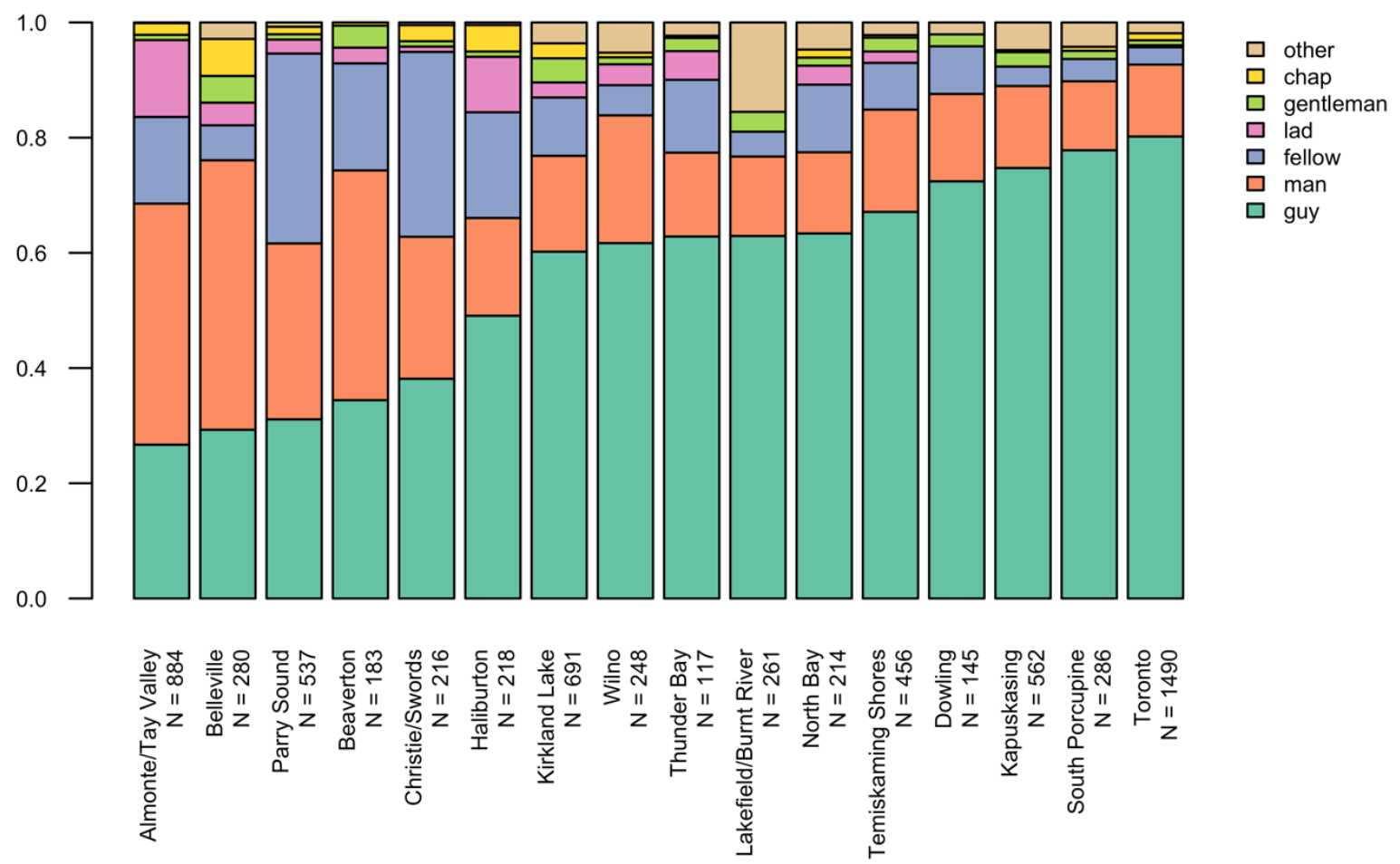

Figure 2: Distribution of the nouns by community of the speaker

Although Table 4 indicated that 'guy' is much more frequent than the other variants in the Ontario communities as a whole, Figure 2 indicates that there are large differences between the communities. First, the relative frequency of the most frequent nouns, 'guy', 'man' and 'fellow' differs per community. For 'guy', for instance, it ranges from 27\% (Almonte/Tay Valley) to 80\% (Toronto), which shows that the variant is clearly diffusing throughout the American English dialects.

Second, the frequency of 'lad' and 'chap', two nouns that are associated with Scots and Irish varieties (see above), is the highest in Almonte/Tay Valley. This can be explained by the fact that these communities have a higher proportion of inhabitants with Scots and/or Irish ancestry (see Tables 1 and 2 above). Thus, this result points to a founder effect, with variants from the original inhabitants of these communities still in use. However, such a founder effect is not all-encompassing. Haliburton also stands out for its use of 'lad' and 'chap', but in this case the proportion of Scots and/or Irish ancestry is comparable to other places. This suggests that there are factors beyond founding populations that play a role in this variation, as we will see.

Third, the order of the communities on the x-axis indicates that there may be a two-way split with regard to the use of $3^{\text {rd }}$ person singular male nouns. More specifically, the communities on the far left of the $x$-axis are Belleville and small Ontario communities (specifically Almonte/Tay Valley, Parry Sound, Beaverton, Christie/Swords (Seguin Township) and Haliburton), while the northern, larger communities (Temiskaming Shores, Kapuskasing, South Porcupine (Timmins)) and the urban centre Toronto are shown on the far right. In the middle of the Figure, there are both northern (Kirkland Lake, Thunder Bay) and more southerly 
communities (Wilno (Barry's Bay), Lakefield/Burnt River (Kawartha Lakes)). This picture may be complicated by the fact the data for the communities on the left of the plot, on average, come from older speakers. For this reason, we will use multifactorial methods to disentangle the effects of year of birth and community.

As a next step, we determine whether the patterns that are found also reflect a change in apparent time. Our data comprise considerable time depth (date of birth 1880's to early 2000's) due to the inclusion of both diachronic and synchronic materials. This aligns our study with D'Arcy's "longue durée" (2015: 455); however, our study is more telescoped in time and interpreted predominantly using the apparent time construct (Bailey et al. 1991). Figure 3 shows the distribution of the variants for $3^{\text {rd }}$ person singular males by decade of birth of the speaker. The figure reveals a notable pattern of linguistic change. Older speakers show the most variation: they do not use 'guy' often, but frequently rely on the other variants (especially 'man' and 'fellow'). As speakers get younger, however, the picture changes. On one hand, for the younger generations, 'man', 'fellow' and the other variants are nearly categorically (in $84 \%$ of the cases for speakers born in the 1990s) replaced with 'guy'. On the other hand, younger speakers also seem to use fewer different word types: older alternatives for a $3^{\text {rd }}$ person singular male like 'lad', 'gentleman' and 'chap' seem to be disappearing from their grammar.
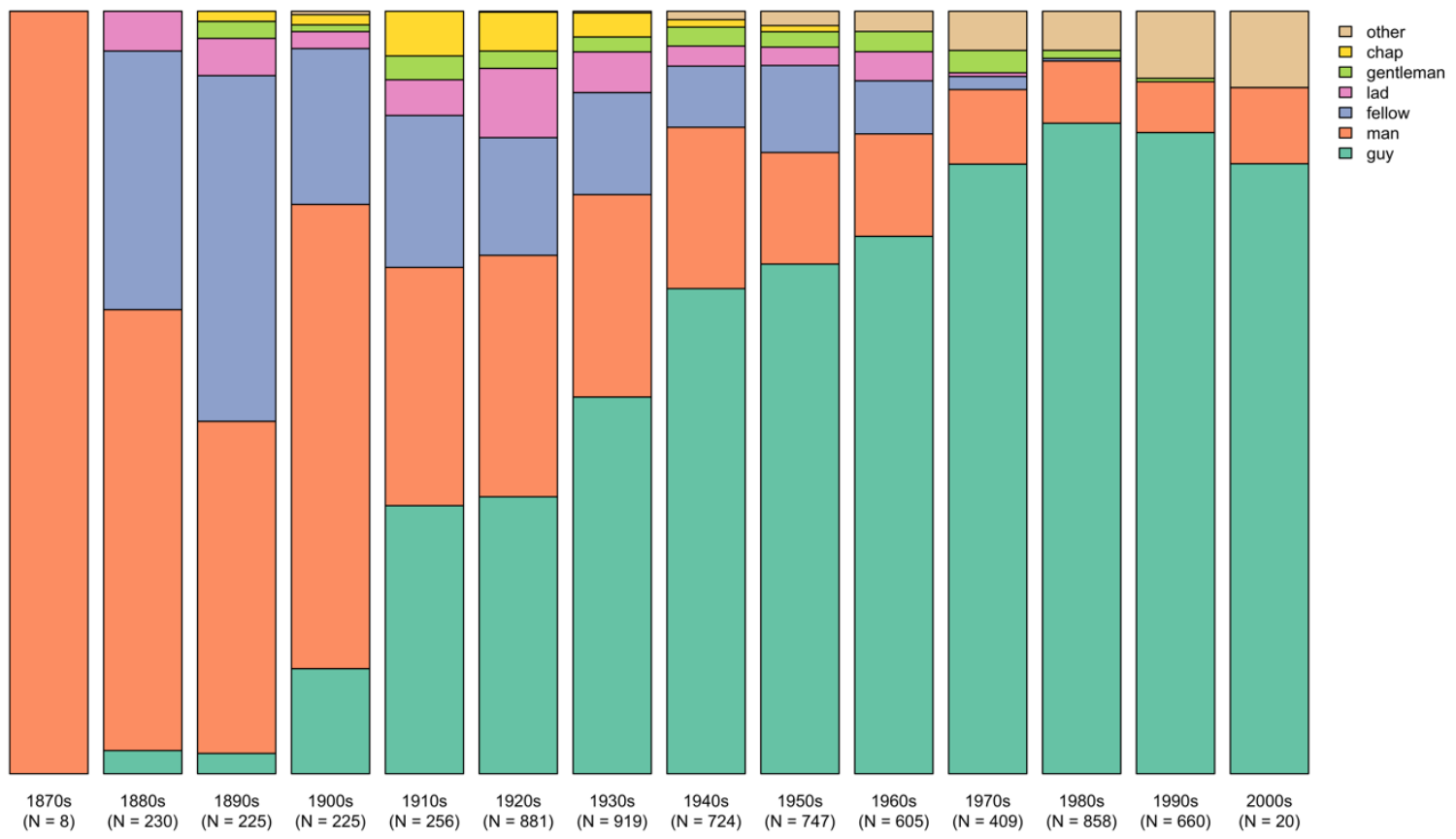

Figure 3: Distribution of nouns by decade of birth of the speaker

However, the frequency of 'other' nouns does increase over time. Figure 4 shows the proportion (in the full dataset) of the other variants that occur less than 200 times by date of birth of the speaker, including 'chap' ( $\mathrm{N}=108)$ and 'gentleman' $(\mathrm{N}=127)$, which are not coded as 'other' in the data. Because the token counts are low ('chap', for instance, is only used 3.62\% of the time by speakers born before 1930), date of birth is recoded into three categories and the total token counts per group are indicated on the $\mathrm{x}$-axis. The figure 
shows that, even for these infrequent variants, a change over time is apparent. More specifically, 'gentleman' and 'chap' have decreased in frequency in the last decades, whereas 'mate', 'buddy' and especially 'dude' are becoming more popular.

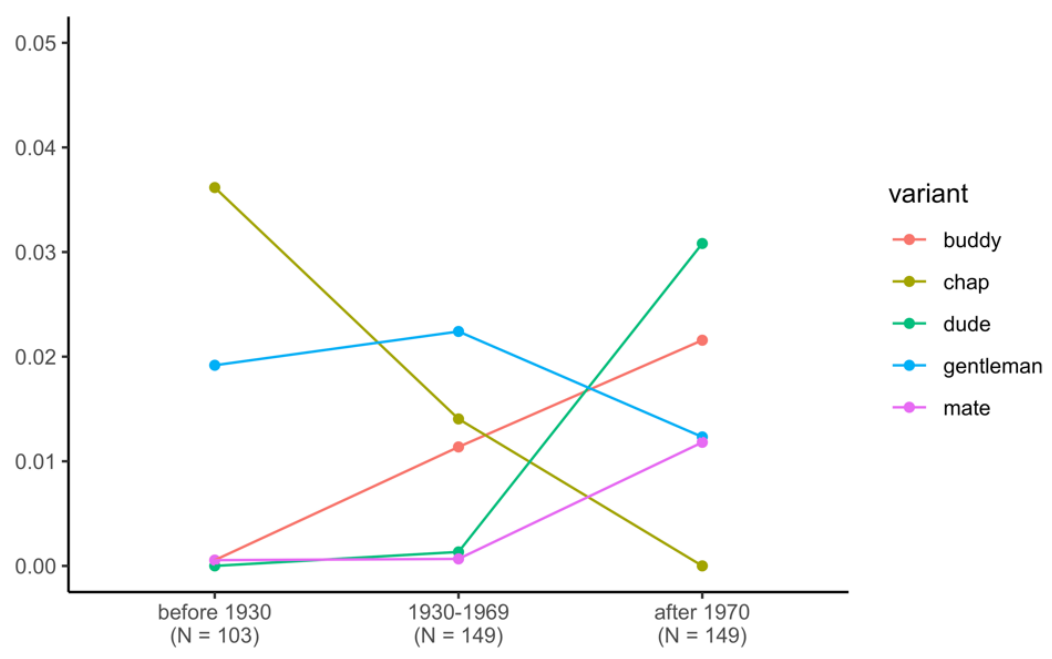

Figure 4: Proportion of non-frequent variants $(\mathrm{N}<200)$ by date of birth in the dataset. Total token counts per group are indicated below the $\mathrm{x}$-axis.

A conditional inference tree (see Tagliamonte \& Baayen 2012) confirms that the effect of community and decade of birth are the most important ones in the data (Figure 5). The simplified conditional inference tree shown in the Figure first splits the data by the decade of birth of the speaker (node 1), and distinguishes older speakers (born before 1940) from younger ones (born in 1940 or later). ${ }^{13}$ The second split in both age groups is by the community of the speaker. The tree indicates that for the older speakers (left branch/node 2) two groups of communities behave similarly. The communities in node 3, with the highest proportion of 'man' and the lowest proportion of 'guy', are mostly the small communities (Almonte/Tay Valley, Beaverton, Belleville, Christie/Swords (Seguin Township), Haliburton and Parry Sound) plus two northern communities (North Bay and Temiskaming Shores). The communities in node 4, where older speakers already use 'guy' relatively frequently, are mostly the northern communities (Dowling, Kapuskasing, Kirkland Lake, South Porcupine (Timmins) and Thunder Bay), two small communities (Burnt River (Kawartha Lakes/Lakefield and Wilno (Barry's Bay)) and the urban centre, Toronto. In the right branch (node 5), two communities are split off in node 6 (viz. Almonte/Tay Valley and Haliburton). In this case, the difference is due to the lower frequency of 'guy' in these communities, and to the higher frequency of 'lad'. In sum, the tree reveals a change in apparent time towards 'guy', with higher proportions of this incoming variant for the younger speakers. Additionally, for the older speakers, the change is more advanced in most of the northern communities and in the urban centre of Toronto. In the next section, we examine whether we find

\footnotetext{
${ }^{13}$ The tree shown in Figure 5 was constructed by choosing 2 as the maximum depth of the tree, to ensure readability. A more complicated conditional inference tree, without a specified maximum depth also first splits by decade of birth and community. In further splits, the social features sex, education level and occupation level, become important as well.
} 
sociolinguistic patterns that may explain the change towards 'guy', by relying on a mixed-effects regression model.

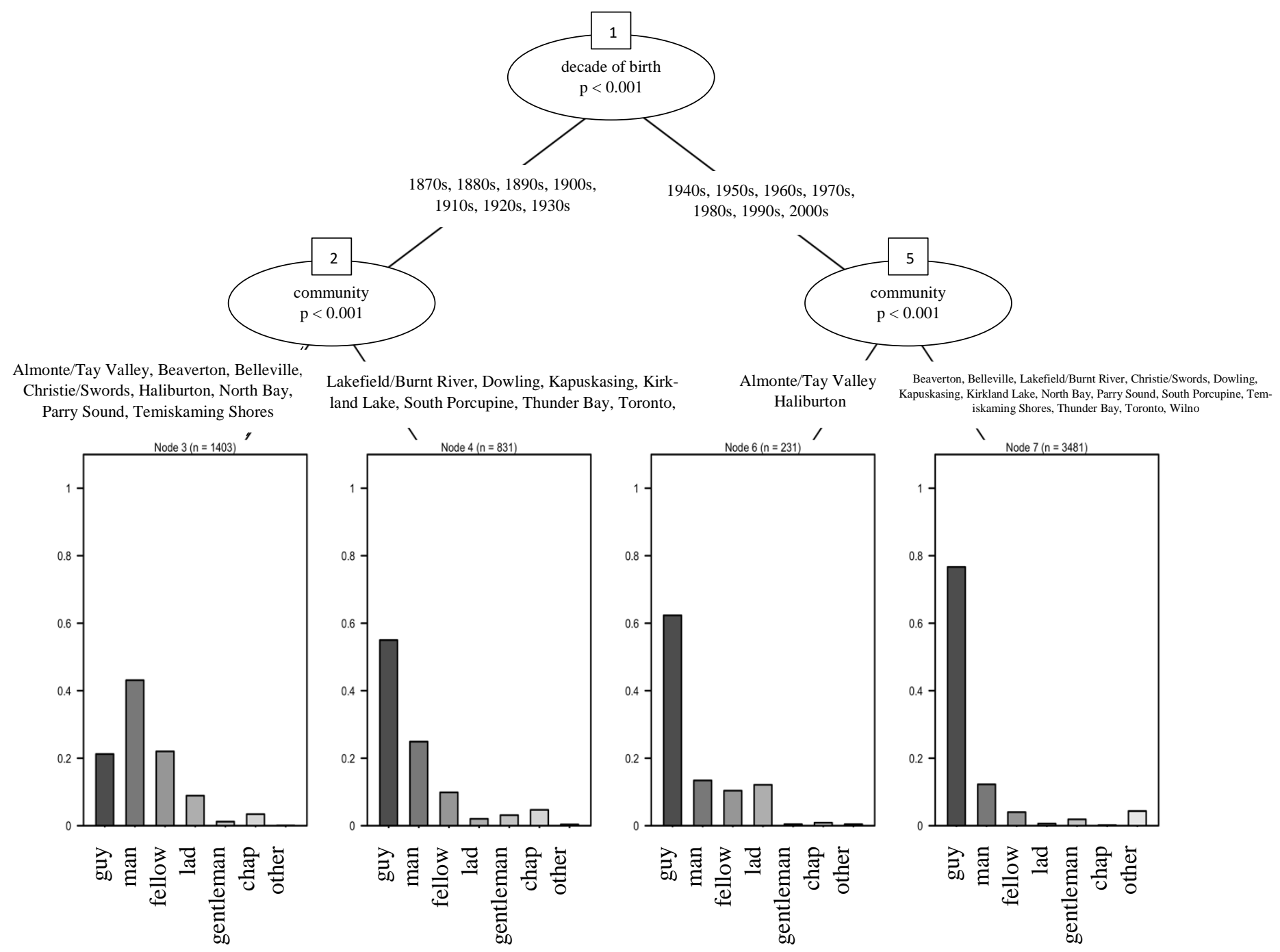

Figure 5: Conditional inference tree 


\subsection{Mixed-effects regression model}

To examine whether there are sociolinguistic factors that influence the change towards 'guy', we use mixedeffects regression modelling. We use a binary operationalization of the $3^{\text {rd }}$ person referring constructions as the response variable (viz. 'guy' or 'anything but guy'). The model contains a random effect for community and for speaker nested in community. We verified whether this random-effects structure is warranted by the data by confirming that this structure explains more variation than models that only have a random effect for speaker or for community. We examined the influence of sex, education level (with or without secondary education), occupation level (white collar or blue collar ${ }^{14}$ ), year of birth (centered around the mean to reduce multicollinearity) and the interaction between them. However, the education level of the speaker does not reach significance in the multivariate environment, nor do most of the interaction effects. Only the interaction between year of birth and occupation level is significant $(p<0.05)$. We checked that there are no harmful correlations between the predictors in a main effects-only model (all VIF $<3$ ) and visually confirmed that the residuals are distributed normally. The power of the model is good, with a $\mathrm{C}$ value of .90 and $82 \%$ correctly predicted observations, which is an acceptable level given the fact that no languageinternal features are included in the analysis.

Table 5 shows the output of the final regression model. The response variable has 'anything but guy' as its reference level $(\mathrm{N}=2547$, or $47.21 \%)$, and predicts the occurrence of 'guy' $(\mathrm{N}=2847$, or $52.78 \%)$. Consequently, significant positive estimates indicate that higher proportions of 'guy' are predicted by the model (we use the usual alpha level of 0.05).

\begin{tabular}{|c|c|c|c|c|}
\hline & Estimate & $p$-value & $\begin{array}{l}\text { Number of } \\
\text { tokens per } \\
\text { group }\end{array}$ & $\begin{array}{l}\% \text { of } \\
\text { tokens per } \\
\text { group }\end{array}$ \\
\hline (Intercept) & 0.7254 & $<0.001$ & & \\
\hline \multicolumn{5}{|l|}{ Main effects } \\
\hline Year of birth (centered) & 0.0470 & $<0.001$ & & \\
\hline \multicolumn{5}{|l|}{ Occupation level (binary) } \\
\hline blue collar & \multicolumn{2}{|c|}{ reference level } & 3002 & $55.65 \%$ \\
\hline white collar & -0.2064 & NS & 2392 & $44.35 \%$ \\
\hline \multicolumn{5}{|l|}{ Sex } \\
\hline male & \multicolumn{2}{|c|}{ reference level } & 3629 & $67.28 \%$ \\
\hline female & -0.8369 & $<0.001$ & 1765 & $32.72 \%$ \\
\hline \multicolumn{5}{|l|}{ Interaction effects } \\
\hline Year of birth (centered) : Occ. level (white-collar) & 0.0147 & $<0.05$ & & \\
\hline
\end{tabular}

Table 5: Output of the fixed effects in the mixed-effects regression model

\footnotetext{
${ }^{14}$ As an anonymous reviewer pointed out, students are generally younger in our data (mean year $\left._{\text {of birth }}=1990\right)$, whereas blue-collar $\left(\right.$ mean $\left._{\text {year of birth }}=1939\right)$ and white-collar workers $\left(\right.$ mean $\left._{\text {year of birth }}=1946\right)$ are older. Because this may skew the results, we do not include the students in the analysis.
} 
The results confirm that there is a change in progress. First, there is a significant interaction between year of birth and occupation level, which is visualized in Figure 6. This Figure confirms that younger speakers (of all occupation levels) are predicted to use 'guy' more frequently than their older peers. Additionally, it reveals an interesting pattern. The difference between the blue-collar and white-collar workers for older individuals shows that 'guy' was initially more frequently used by speakers from the former group. However, more recently, it has been picked up by white-collar workers as well, with the youngest white-collar individuals even using it more often than their blue-collar peers. This confirms that, as already described in Tagliamonte (to appear), the diffusion of 'guy' across communities and over time originates from the lower socio-economic groups in the communities, suggesting we are witnessing the spread of a non-prestigious variant. This is also confirmed by the effect of sex in the data (Table 5). The predicted frequency of 'guy' for men is significantly higher than that of women. Thus, in contrast with principles 3 (change from above; cf. Labov 2001) and 4 (change from below), male speakers seem to be the leaders of this linguistic change.

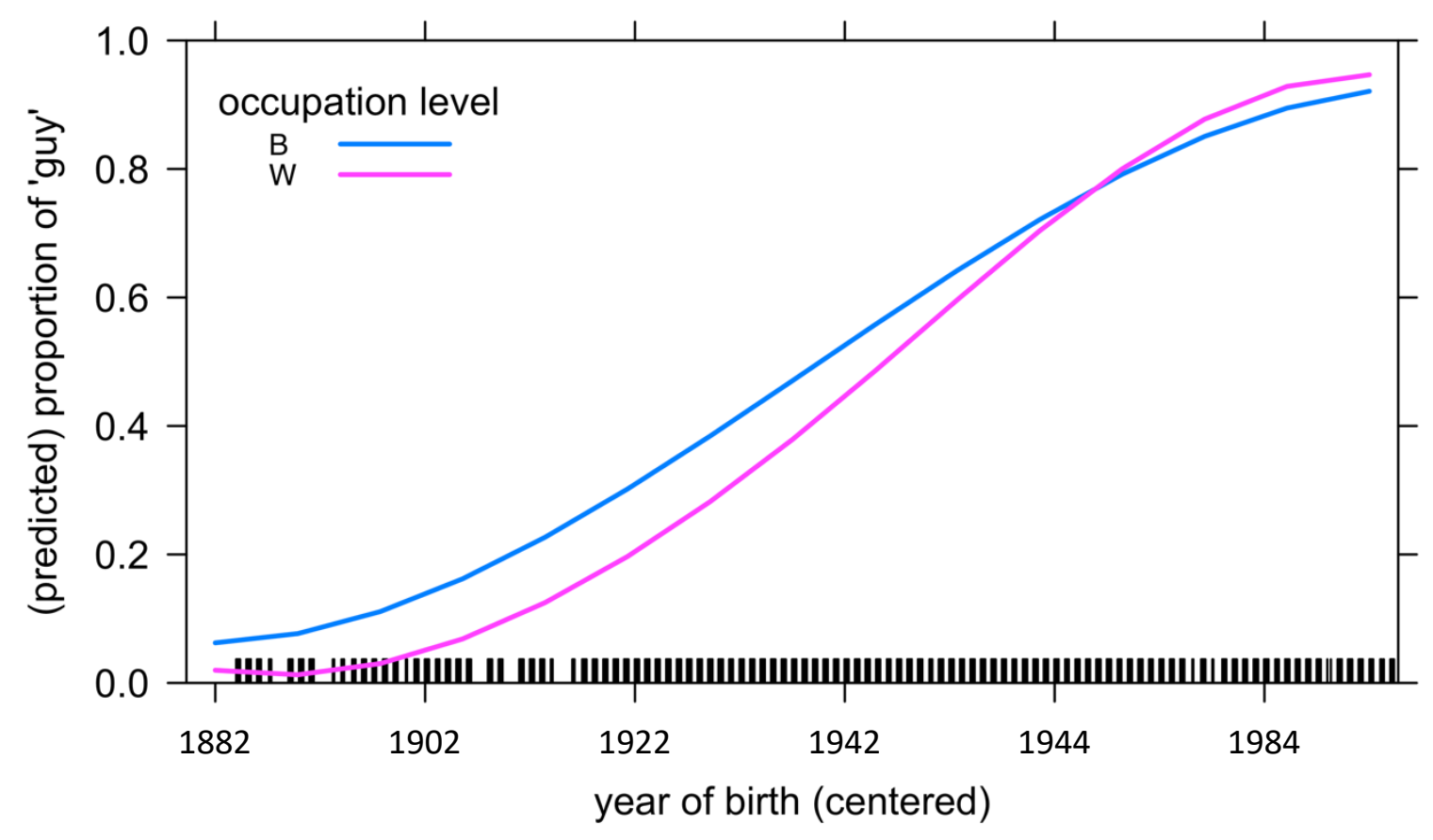

Figure 6: Interaction between year of birth and occupation level. The year of birth variable is centered around the mean in the model. The plot shows the original values on the $\mathrm{x}$-axis.

Changes led by men are less frequent in language change in progress (Labov 2001: 284). Nonetheless, Labov (2001: 315-319) has asserted that that they are characterized by a pattern of women from higher social classes distancing themselves from the change more than working class women - a pattern that is the inverse of the social class patterning that men show for female-led changes:

"Male recession from a female-dominated change is $[\ldots]$ asymmetrically matched by a female recession from a male-dominated change. [...] For a female-dominated change, male distancing is 
inversely related to status; for a male-dominated change, female distancing is directly related to status" (Labov 2001: 318-319).

Thus, an additional question is whether there is an interaction effect of occupation level by sex present in the data.

Although this interaction does not reach significance in the regression model, this may have to do with the complexity of the data, which is not only characterized by sociolinguistic and apparent-time differences, but also comprises communities at different stages of the change. To further confirm the importance of men in the change towards 'guy', Figure 7 shows the proportion of 'guy' vis-à-vis the other variants by speaker sex and occupation level (blue collar (B), white collar (W)). If blue- and white-collar workers are compared, the sex difference predicted by Labov seems to exist in the data. Whereas 'guy' is used at similar rates by bluecollar men $(50.78 \%)$ and blue-collar women $(53.74 \%)$, for white collar workers, the difference is much larger (62.10\% for men vs. $46.13 \%$ for women). This difference is mostly related to the fact that the whitecollar women use 'man' more (37.68\%) than the male speakers (17.04\%). As a result, even though the pattern that is shown in the Figure does not reach significance in a multivariate environment, we do find preliminary evidence confirming Labov's predictions, that women from the higher social group distance themselves from the male-led change the most.

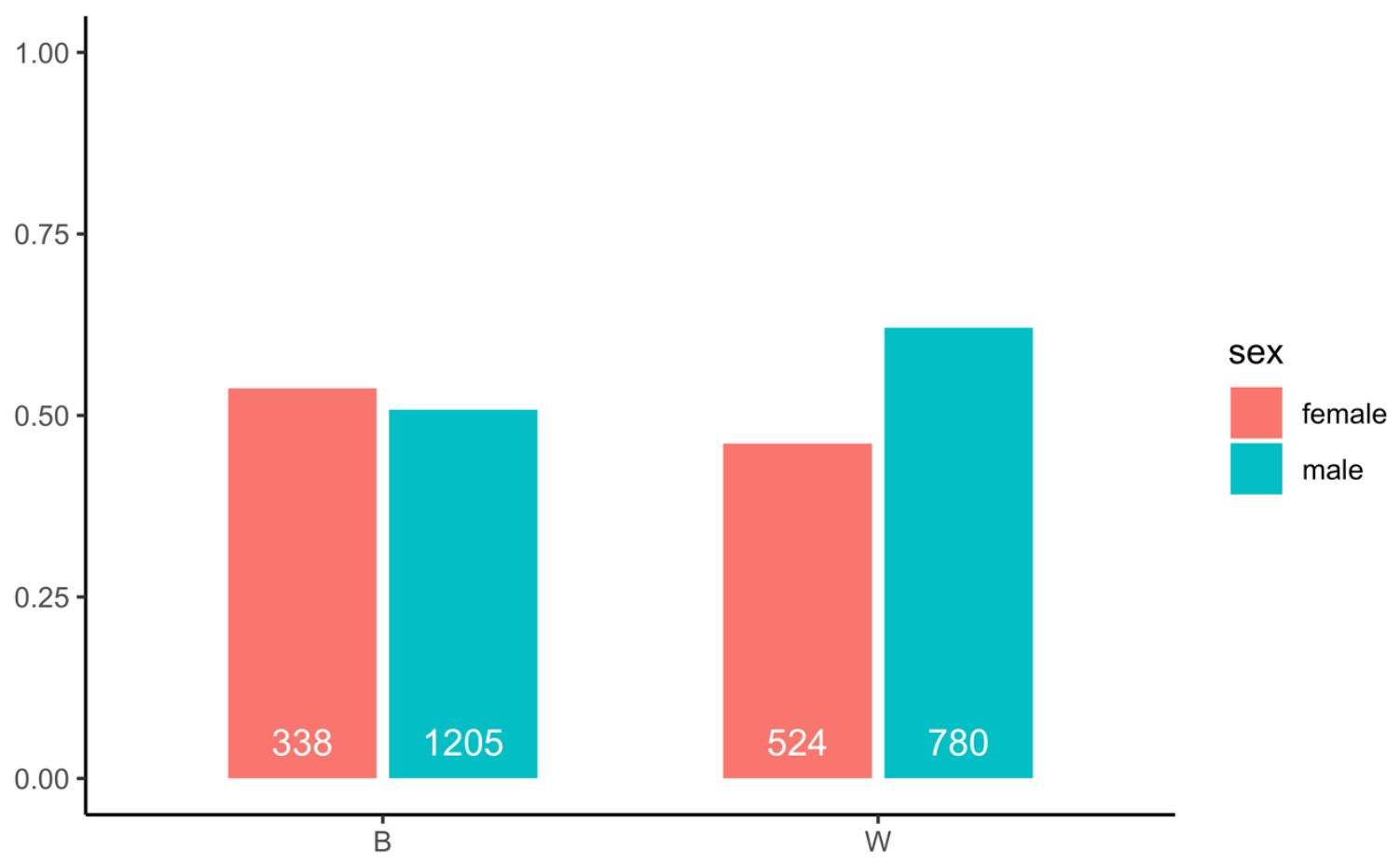

Figure 7: Proportion of 'guy' by sex and occupation level. The figures at the bottom of each bar indicate the number of tokens of 'guy' per group. 
Next, we turn to the results for the random effects. Table 6 shows the variance and standard deviation associated with the random effects. Figure 8 visualizes the random intercepts per community. In particular, this Figure shows the differences between the predicted proportion of 'guy' vis-à-vis other variants per community, over and above the sociolinguistic features included in the regression model. The figure reveals a modest trend that resembles the pattern in Figure 2: the largest negative intercept adjustments (at the bottom of the figure) are for Almonte/Tay Valley but also for Belleville, which indicates that they use the 'anything but guy' nouns quite a lot, and 'guy' relatively infrequently. For Toronto, however, positive intercept adjustments are predicted by the model, which confirms that the chance of an individual using 'guy' is higher there. For the other communities, the confidence intervals (i.e. the lines in the Figure per community) contain 0 , which indicates that their interpretation is less reliable and should be treated with caution. It seems that most of the northern communities have positive intercept adjustments and, thus, a larger than expected proportion of 'guy'. However, not all communities follow this trend. North Bay, has a negative intercept, and Burnt River/Lakefield and Parry Sound, two small communities are predicted with a larger proportion of 'guy' than expected.

\begin{tabular}{|l|l|l|l|}
\hline & Name & Variance & Standard deviation \\
\hline speaker:community & (Intercept) & 1.9821 & 1.4079 \\
\hline community & (Intercept) & 0.2648 & 0.5146 \\
\hline
\end{tabular}

Table 6: Variance and standard deviation of the random effects in the mixed model

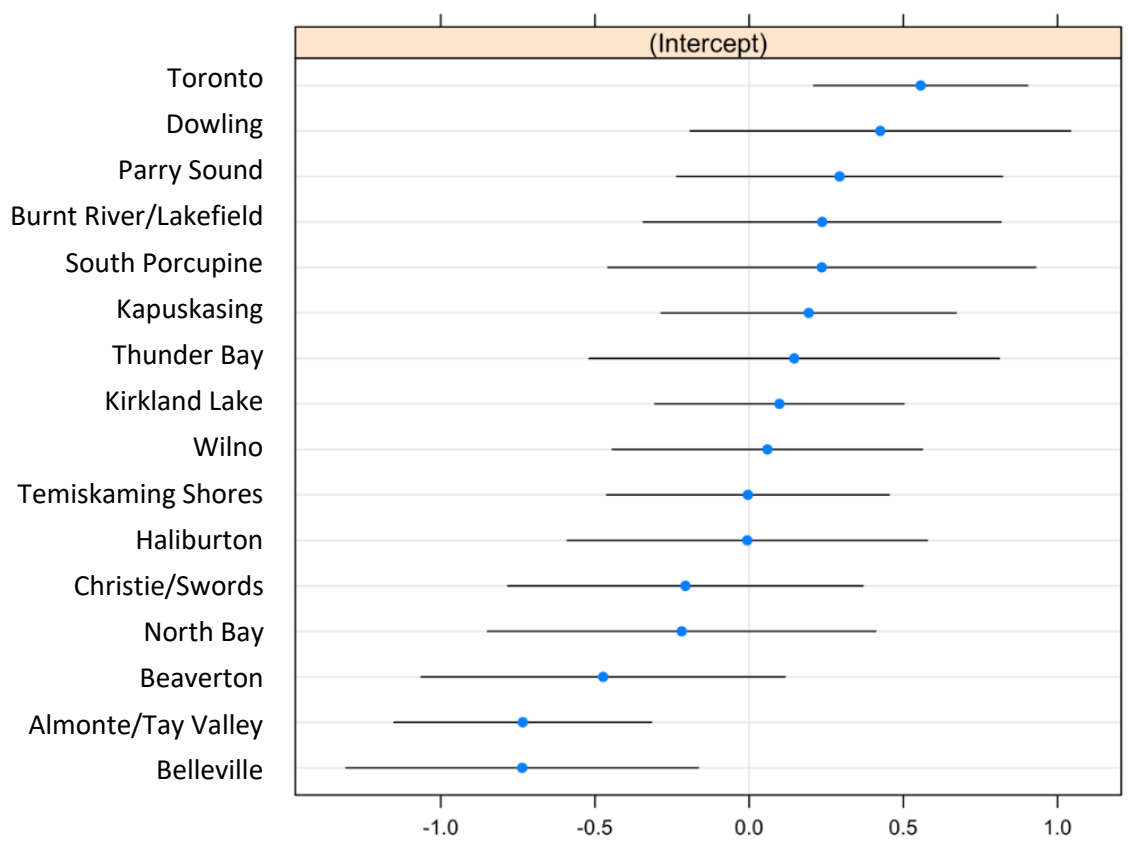

Figure 8: Visualization of the random intercepts per community 


\section{Discussion and conclusion}

We have now probed the sociolinguistic and geographical distribution of the nouns used for $3^{\text {rd }}$ person singular male referents in the dialects of Ontario. The apparent-time results demonstrate that there is a change in progress: speakers born before 1940 show variation with regard to their use of 'man', 'guy' and other less frequent variants like 'fellow', 'lad' and 'chap' but younger speakers use 'guy' nearly categorically.

The gradual loss of variants associated with the founder dialects is consistent with the well-known standardization of Canadian English in the $20^{\text {th }}$ century, which resulted in widespread homogenization (see Chambers 2003, Priestly 1951). As Chambers (2012:471) notes: "With standardization, communities that once used local forms that differentiated them from their neighbours replace them with non-local forms." This is precisely the overarching trend observed here: Ontario dialects are losing the rich set of variants (like 'fellow', 'gentleman' or 'lad') they once had for $3^{\text {rd }}$ person male referents and are converging towards a single form (Figure 3).

The sociolinguistic correlates reveal that men and blue-collar workers are leading this change. We also found evidence for an interaction between social class and sex, although this did not reach significance in the multivariate model. Specifically, Figure 7 shows that women from the highest socio-demographic group (viz. women with the highest occupation level) show lower frequency of 'guy'. This was explained by the fact that they use 'man' more. These sociolinguistic correlates suggest that 'guy' is a vernacular form, especially in comparison to 'man', that is diffusing across Ontario through a change from below. Further evidence for this interpretation comes from the fact that the pattern found with regard to sex is typical for unconscious change from below (Labov 2001).

Although the Ontario Dialects Project does not systematically ask for information of speakers' views on language, we have found some preliminary evidence indicating that speakers are aware that the $3^{\text {rd }}$ person male referent variable is undergoing change $(12 a, b)$.

(12) a. Lately I've- I've been finding myself saying bud or buddy quite a bit. Um I think that stems from my cousin too, like you see someone in the hall, "Hey buddy!" (John Courchaine, M, 18, Kapuskasing)

b. Ah, oh my God, there were so many crazy words then. I just don't even remember what they were um ... Dude! We used to say all the time. Like, "Dude!" I still hear people say that and I laugh at them, but. "Oh Dude, that was so lame. Yeah, Dude" (laughs) (Neha Jairath, F, 27, Toronto)

Further, we have no evidence for speakers noticing an increase in using 'guy'. If there is actually no metaawareness of this change, we can take this as further evidence that we have uncovered a change from below. Of course, absence of evidence is not evidence of absence, so follow-up research is necessary to support this interpretation. For example, another correlate of changes from below is style-shifting (cf. Coates 2016: 185). However, since the Ontario Dialects Project is entirely conversational data we do not have the data to probe this possibility. Thus, another interesting study would be to follow up this one with an examination of the use of $3^{\text {rd }}$ person male referents across varying contexts.

The change to 'guy' has left visible geographic patterns by way of contrasts in usage in the Ontario communities since its use is not, or not yet, equally advanced in all places. Indeed, the data reveal a striking geographical pattern (Figure 2). Communities like Almonte and Tay Valley have a high proportion of 'lad'. Given the synchronic evidence from Scotland and the ample attestations in both Scots and Irish dictionaries, 
we suggest that this is a lingering founder effect based on the fact that these places have the highest proportion of Scottish and Irish origin speakers. Similar findings have been described for these communities before with respect to other lexical items, e.g. 'wee' (Tagliamonte to appear), preterit 'come' (Jankowski \& Tagliamonte 2017).

A second geographical pattern is exposed in the change towards 'guy'. Even though this variant is associated with American English in the literature, it is not used throughout the Ontario communities in a similar way. More specifically, as Figure 2 shows, 'guy' is used the most in Toronto and in the larger communities of northern Ontario. In contrast, in the small southerly communities, the change towards 'guy' is less evolved. These findings are somewhat complicated by the fact that our data were collected at various time points, as the pattern is less clear in the regression model (Figure 8). Still, the overall trend resembles what would be predicted on the basis of the cascade and gravity models of spatial diffusion: 'guy' is further evolved (more frequent) in the larger cities in northern Ontario than in the smaller towns. However, the patterning does not conform entirely to the predictions of these models. One notable exception is, for instance, Belleville, a town in the south of Ontario with a relatively large population (50,716; Statistics Canada 2017), but with a very small proportion of 'guy'. According to both the cascade and gravity model, Belleville would be expected to have the highest proportion of 'guy' after Toronto because it is both large in size and close to Toronto. In this case, the longitudinal history of this town as a bastion of Loyalist settlement (i.e. Americans loyal to the crown) may be a factor (Tagliamonte \& Denis 2014). Thus, there is no absolute correlation between community and frequency of 'guy' because so many other factors are at play simultaneously, not the least of which is the number of speakers by generation in our samples.

The overall division of the communities may instead mirror an urban vs. rural division in the Ontario dialects, a factor that is preeminent in studies of Ontario in other disciplines (e.g. Cartwright \& Allan 2002). Recall that the communities in the north have notably different histories than those in the south. Additionally, Toronto and the northern communities have larger population sizes on average. In contrast, in the rural communities, the social network ties are much stronger (Tagliamonte 2014, Tagliamonte \& Denis 2014), which may lead to a stronger retention of older (Scots and Irish) variants. One question that remains is whether the differences between the communities that we have found, is the same for other types of variants (e.g. Jankowski \& Tagliamonte to appear). It is possible that the small communities are, on average, lagging behind in the change towards 'guy' precisely because the use of local variants is consistent with their allegiance to rural values. Further research is necessary to examine these questions; however, they are beyond the scope of the current study.

In sum, by conducting a distributional and multivariate analysis of the use of a linguistic variable that has not gained much attention in previous research, we have uncovered a complex example of homogenization in a change in progress that is led by men. By first focusing on all the possible synonyms for 'guy', and then examining the overall change towards the incoming variant in a multivariate model, we have shown that the pathway of change is heavily influenced by broad sociolinguistic features, but at the same time modulated by community-based characteristics. 


\section{Acknowledgements}

We are grateful to two anonymous reviewers and to the editorial board for their insightful comments on an earlier version of this paper. The second author gratefully acknowledges the Social Sciences and Humanities Research Council of Canada (SSHRC) for research grants 2001-present and the Canada Research Chairs program (CRC) in Language Variation and Change. We are indebted to the many fieldworkers and employees of the UofT Variationist Sociolinguistics Lab. We are grateful to the following scholars and sources for some of the data used in this work : Rebecca Roeder for the Thunder Bay data; Graeme Gordon and Kaye Rogers for the Tay Valley data; Professor Emeritus Ian Pringle (Carleton University) for the Lanark County data, from the 1975-1980 Linguistic Survey of the Ottawa Valley; John MacFie and the Parry Sound District Historical Society for the Parry Sound data; the Hastings County Historical Society for the 1975 Belleville Oral History Project Archive; the Museum of Northern History for the Kirkland Lake 1983 data; the Cobalt Mining Museum for the 1990 Cobalt data.

\section{Author bios}

Karlien Franco holds a PhD in Linguistics from KU Leuven and Radboud University Nijmegen. In 2019 she joined the Variationist Sociolinguistics Lab at the University of Toronto as a postdoc working on the Ontario Dialects Project (most recently Tagliamonte 2013-2018). At present, she is a postdoctoral fellow at the QLVL research group of KU Leuven.

Sali A. Tagliamonte is a Professor of Linguistics at the University of Toronto, Canada. She is the author of six books, including "Making Waves" and "Variationist Sociolinguistics" (Wiley-Blackwell 2012, 2015) and "Analysing Sociolinguistic Variation" and "Roots of English" (CUP 2006, 2013). She has published on Canadian and British English dialects, teen language and television. Her research focusses on morpho-syntactic and discourse-pragmatic features using cross-community comparisons and apparent time to explore linguistic change.

\section{References}

Baayen, Harald R. (2008). Analyzing Linguistic Data: A Practical Introduction to Statistics Using R. Cambridge: Cambridge University Press.

Bailey, Guy, Tom Wilke, Jan Tillery \& Lori Sand. (1991) The apparent time construct. Language Variation and Change 3(3), 241-264.

Britain, David. (2013). Space, diffusion and mobility. In J.K. Chambers \& Natalie Schilling (eds.), The Handbook of Language Variation and Change. Chichester: Wiley-Blackwell. 471-500.

Cartwright, Fernando \& Mary K. Allan. (2002). Understanding the rural-urban reading gap. Statistics Canada. Catalogue no. 81-595-M1E2002001.

Chambers, J.K. (2003). Sociolinguistic Theory: Linguistic Variation and its Social Significance. Malden/Oxford: Blackwell Publishers.

Chambers, J.K. (2012). Homogeneity as a sociolinguistic motive in Canadian English. World Englishes 31(4), 467477.

Coates, Jennifer. (2016). Women, Men and Language. A Sociolinguistic Account of Gender Differences in Language. London/New York: Routledge. 
D’Arcy, Alexandra. (2015). Stability, stasis and change. The longue durée of intensification. Diachronica 32(4), 449-493.

Goebl, Hans. (2006). Recent advances in Salzburg dialectometry. Literary and Linguistic Computing 21(4), 41135 .

Jankowski, Bridget \& Sali A. Tagliamonte. (2017). A lost Canadian dialect: The Ottawa Valley, 1975-2013. In Tanja Säily, Arja Nurmi, Minna Palander-Collin and Anita Auer (eds.), Exploring Future Paths for Historical Sociolinguistics. Amsterdam: John Benjamins. 213-232.

Jankowski, Bridget \& Sali A. Tagliamonte. (To appear). Urban-rural dimensions to variable -body/-one: The case of Ontario, Canada. In Arne Ziegler, Stefanie Edler, Nina Kleczkowski and Georg Oberdorfer (eds.), Urban Matters. Current Approaches of International Sociolinguistic Research. Amsterdam: John Benjamins.

Kiesling, Scott F. (2004). Dude. American Speech 79, 281-305.

Labov, William. (2001). Principles of Linguistic Change. 2: Social factors. Oxford: Blackwell.

Labov, William. (2003). Pursuing the cascade model. In Peter Trudgill, David Britain \& Jenny Cheshire (eds.), Social Dialectology: In Honour of Peter Trudgill. Amsterdam: John Benjamins. 9-22.

Labov, William. (2007). Transmission and diffusion. Language 83(2), 344-387.

Metcalf, Allan. (2019). The Life of Guy. Guy Fawkes, the Gunpowder Plot and the Unlikely History of an Indispensable Word. Oxford: Oxford University Press.

Priestly, F.E.L. (1951). Canadian English. In Eric Partridge \& John W. Clark (eds.), British and American English since 1900. London: Andrew Dakers. 72-79.

Séguy, Jean. (1971). La relation entre la distance spatiale et la distance lexicale. Revue de Linguistique Romane 35, 335-357.

Smith, Jennifer. (2013-2016). One Speaker, Two Dialects: Bidialectalism across the Generations in a Scottish Community. Economic and Social Research Council.

Smith, Jennifer, David Adger, Brian Aitken, Caroline Heycock, E. Jamieson \& Gary Thoms. (2019). The Scots Syntax Atlas. University of Glasgow. http://scotssyntaxatlas.ac.uk

Speelman Dirk. (2014). Logistic regression: A confirmatory technique for comparisons in corpus linguistics. In: Dylan Glynn \& Justyna A. Robinson (eds.), Corpus Methods for Semantics: Quantitative Studies in Polysemy and Synonymy. Amsterdam: John Benjamins. 487-533.

Statistics Canada. (2017). Census Profile 2016. Retrieved on 3 April 2019 from https://www12.statcan.gc.ca/census-recensement/2016/dp-pd/prof/index.cfm?Lang=E.

Tagliamonte, Sali A. 2003-2006. Linguistic changes in Canada entering the 21st century. Research Grant. Social Sciences and Humanities Research Council of Canada (SSHRC).

Tagliamonte, Sali A. (2013). Comparative Sociolinguistics. In J.K. Chambers \& Natalie Schilling (eds.), The Handbook of Language Variation and Change. Chichester: Wiley-Blackwell. 128-156.

Tagliamonte, Sali A. (2013-2018). Social Determinants of Linguistic Systems. Insight Grant: Social Sciences and Humanities Research Council of Canada (SSHRCC).

Tagliamonte, Sali A. (2014). System and society in the evolution of change: The view from Canada. In Eugene Green \& Charles F. Meyers (eds.), The Variability of Current World Englishes. Cambridge: Cambridge University Press. 199-238.

Tagliamonte, Sali A. (To appear). Dialects as a mirror of historical trajectories: Canadian English across Ontario (North America). In Merja Kytö \& Lucia Siebers (eds.), Early American Englishes. Amsterdam/Philadelphia: John Benjamins.

Tagliamonte, Sali A. \& R. Harald Baayen. (2012). Models, forests and trees of York English: Was/were variation as a case study for statistical practice. Language Variation and Change 24(2), 135-178.

Tagliamonte, Sali A. \& Derek Denis. (2014). Expanding the transmission/diffusion dichotomy: Evidence from Canada. Language 90(1), 90-136.

Trudgill, Peter. (1974). Linguistic change and diffusion: Description and explanation in sociolinguistic dialect geography. Language in Society 3, 215-246. 